\title{
Residual strain analysis with digital image correlation method for subsurface damage evaluation of hinoki (Chamaecyparis obtusa) finished by slow-speed orthogonal cutting
}

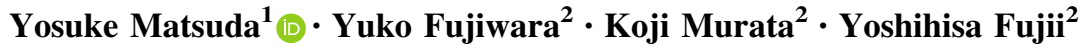

Received: 1 February 2017 / Accepted: 19 July 2017/Published online: 8 September 2017

(C) The Japan Wood Research Society 2017

\begin{abstract}
A digital image correlation (DIC) method was applied to measure strain which arose and remained beneath the finished surface in slow-speed orthogonal cutting of hinoki (Chamaecyparis obtusa), to evaluate the damage in the subsurface cell layers. While the quartersawn surface was cut parallel to the grain, the side surface, flat-sawn surface, was captured by a high-speed camera. The images were analyzed to calculate strain in a region of $0.67 \times 0.22 \mathrm{~mm}$ allocated beneath the finished surface. Almost no strain normal to the cutting direction was detected for the depth of cut and cutting angles, $0.05 \mathrm{~mm}$ and smaller than $60^{\circ}$, respectively. For the depths of cut and cutting angles, larger than $0.1 \mathrm{~mm}$ and smaller than $60^{\circ}$, respectively, the fore-split induced tensile strain normal to the cutting direction, although it hardly remained after the cutting. The compression strain normal to the cutting direction clearly remained for the cutting angles larger than $70^{\circ}$, regardless of the depths of cut employed in this study. The subsurface damage assumed from the residual strain distribution corresponded to the appearance of the subsurface layer in the X-ray computed tomography (CT) images. It was also revealed, and the DIC program
\end{abstract}

A part of this article was presented at the 65th Annual Meeting of the Japan Wood Research Society, Tokyo, Japan, March 2015, and also at the 33rd Annual Meeting of Wood Technological Association of Japan, Sapporo, Japan, October 2015.

Yosuke Matsuda

yosukem@ffpri.affrc.go.jp

1 Forestry and Forest Products Research Institute, 1 Matsunosato, Tsukuba, Ibaraki 305-8687, Japan

2 Graduate School of Agriculture, Kyoto University, Kitashirawakaoiwake-cho, Sakyo-ku, Kyoto, Kyoto 606-8502, Japan could not always measure excessively large strain correctly.

Keywords Orthogonal cutting - Digital image correlation · Residual strain

\section{Introduction}

Wood cutting is a process to remove the unneeded part of the workpiece as a chip to create a newly finished surface. The finished surface without defects such as torn grain or raised grain is considered to be of good quality. In the cutting process, large strain over the elastic limits may arise in the workpiece, depending on the cutting force applied by the cutting tool. Large tensile, compression, or shear strain may remain in the cell layers even after the cutting, and those cell layers are regarded as damaged. The damage near the path of the cutting edge is especially related to the defects on the surface. For example, the cells which are compressed by the cutting tool may transform into raised grain when they swell by absorbing water in atmosphere, adhesive, or finishing solvents [1]. The authors have investigated the finished surface and subsurface structure using an X-ray computed tomography (CT) system, and discussed the relation between the "Chip Type" and the damage [2]. The study indicates that the damage is closely related to the cutting condition employed, and the cutting condition which minimizes the damage should be employed for better quality of machined surface. However, the occurrence of the damage has not been discussed from the viewpoint of the two-dimensional strain distribution near the path of the cutting edge.

Some studies have been conducted to analyze stress and strain distribution in the workpiece during the wood cutting 
[3-12]. The photoelastic-coating method was applied for the analysis of cutting stress $[3,4]$. McKenzie et al. used grid patterns printed on the side surface of the workpiece for measuring strain in veneer cutting $[11,12]$. However, some time-consuming operations on the wood surface are needed in these methods.

Digital image correlation (DIC) method, which is also known as digital speckle photography (DSP) method, is a non-contact method that measures strain on the surface of a material which undergoes deformation by comparing the local grayscale pattern of the digital images captured before and after the deformation. DIC method was developed by Peters et al. [13] and Sutton et al. [14] in the 1980 s, and it has been widely used to calculate strain in various materials [15]. DIC method is useful in a case, where specimen is so small that strain gauge cannot be attached [16]. Moreover, preparation on the surface of the material is not always necessary as long as the specimen has a random speckle pattern on its surface, which is essential for applying DIC method [17]. One of the earliest applications of DIC method to the measurement of strain in a wood specimen was conducted by Choi et al. [18]. Since then, the DIC method has been widely applied for analyzing the deformation of wood and wood-based materials in compression tests [19-25], in tensile tests [16, 26-35], in drying or swelling tests [36-38], and so on. Hellström et al. applied DSP method to determine the deformation of wood in a chipping process [39]. However, the relation between the machining defects and the strain distribution has not been discussed, since the main concern of the chipping process is the quality of the chip, not the quality of the surface.

In this study, two-dimensional strain distribution beneath the surface of hinoki (Chamaecyparis obtusa) finished by the cutting process was measured in an attempt to assess damage in cell layers beneath the finished surface. Slow-speed orthogonal cutting was conducted and the side surface of the workpiece was captured with a high-speed camera during and after the cutting. The images before and after the cutting were analyzed using a DIC method. The residual strain as an indicator of the damage and its relation to the cutting condition were investigated.

\section{Materials and methods}

\section{Cutting experiment}

The schematic diagram of the cutting experiment is shown in Fig. 1. Orthogonal cutting was conducted by feeding the cutting tool toward the workpiece at a constant speed of $5 \mathrm{~mm} / \mathrm{s}$ by a motorized linear stage. The tool was fed

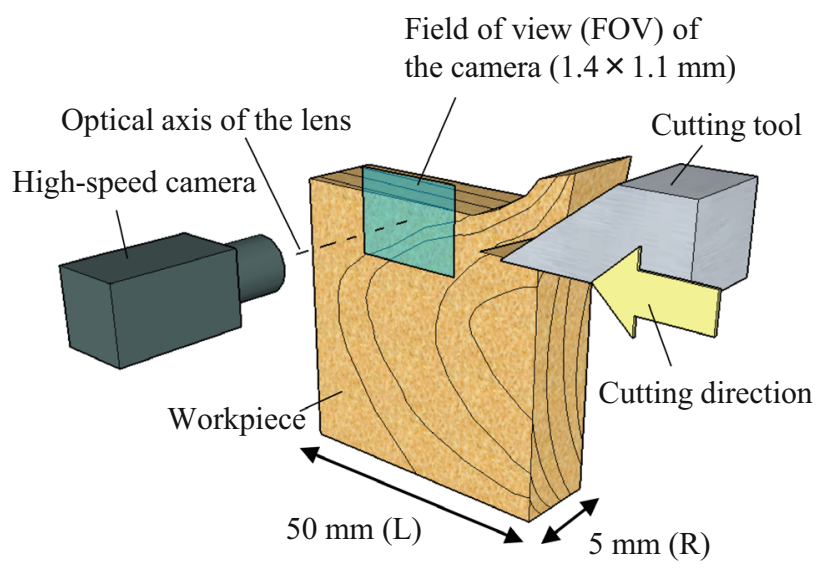

Fig. 1 Schematic diagram of cutting experiment

parallel to the grain without bias angle so as to eliminate the out-of-plane deformation. The finished surface was the quarter-sawn surface of hinoki (Chamaecyparis obtusa). The size of the workpiece was $5 \mathrm{~mm}$ in radial (R) direction and $50 \mathrm{~mm}$ in both longitudinal $(\mathrm{L})$ and tangential $(\mathrm{T}) \mathrm{di}-$ rections. The air-dry density was $0.38 \mathrm{~g} / \mathrm{cm}^{3}$, and the moisture content was $10.6 \%$. The wedge angle of the cutting tool varied from $25^{\circ}$ to $75^{\circ}$ at intervals of $10^{\circ}$, while the clearance angle was kept constant at $5^{\circ}$, so the cutting angles employed were $30^{\circ}-80^{\circ}$ at intervals of $10^{\circ}$. The tools were made of high-speed steel (SKH51), and their rake faces were coated with $5-\mu \mathrm{m}$-thick chromium nitride. The depth of cut employed was $0.05,0.1,0.2$, or $0.3 \mathrm{~mm}$. The cutting was conducted five times for every combination of cutting angle and depth of cut, and the workpiece was randomly exchanged for each time.

A video clip of the chip formation was taken with a high-speed camera (VW-6000, KEYENCE). The optical axis of the lens of the camera was perpendicular to the LT surface of the workpiece, and the camera always took pictures of a certain area of the LT surface. The field of view (FOV) of the camera was $1.4 \mathrm{~mm}$ (640 pixel) in horizontal direction (L direction) and $1.1 \mathrm{~mm}$ (480 pixel) in vertical direction ( $\mathrm{T}$ direction). The video clip was recorded at a shutter speed of $1 / 2000$ or $1 / 3000 \mathrm{~s}$ and a frame rate of $250 \mathrm{fps}$. The video clip was converted into a sequence of 8-bit grayscale images using software ImageJ (ver1.50e) [40].

\section{Digital image correlation analysis}

DIC program used in this study was coded by us in MATLAB (2016) language [41]. A grayscale image captured before the cutting was selected as a reference image, while several images captured in the cutting process were selected as deformed images. A region of interest (ROI) 
Fig. 2 Region of interest (ROI) and reference pixels in a reference image. The yellow colored area represents the ROI. The red dashed line represents the path of the cutting edge. Each white square represents a reference pixel. The red rectangle represents the subset of the reference pixel marked in red (color figure online)

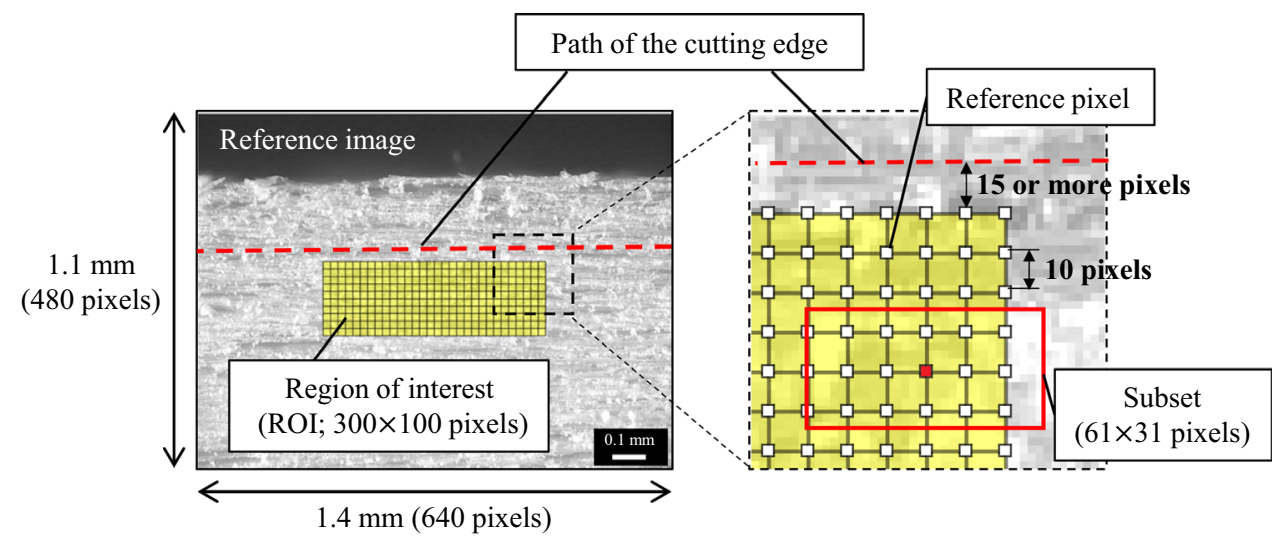

was defined in the reference image, as shown as the yellow colored area in Fig. 2. The ROI measured $300 \times 100$ pixels $(0.67 \times 0.22 \mathrm{~mm})$, and was divided into square grid. The grid size was 10 pixels $(0.02 \mathrm{~mm})$. Each grid point was designated as reference pixel (white square in Fig. 2). A group of pixels around a reference pixel was designated as a reference subset (red rectangle in Fig. 2). The reference pixel was located in the center of its subset. The width and the height of the subset were 61 and 31 pixels, respectively.

The target subset whose grayscale pattern is the most similar to the reference subset was found from the deformed image, and the displacement of the reference pixel due to the deformation was estimated. The similarity between the two subsets was evaluated based on zero-mean normalized cross-correlation (ZNCC) coefficient, $C_{\mathrm{ZNCC}}$ [42], which was given by the following formula: interpolated pixels. Thus, the number of the interpolated pixels between the two reference pixels was $2^{7}-1=127$. The grayscale value of the interpolated pixels was determined using spline interpolation. The minimum displacement components, $u$ and $v$, that the DIC program could measure were both $(1 / 2)^{7} \cong 0.8 \times 10^{-2}$ pixels.

The reference subset located near the path of the cutting edge should contain a featureless grayscale pattern of the air after the chip was removed. In such cases, ZNCC coefficient would decrease, which may lead to erroneous displacement calculations. Therefore, the upper side of ROI (Fig. 2) was placed at least 15 pixel $(0.03 \mathrm{~mm})$ apart from the path of the cutting edge, so that the subsets should not contain the featureless grayscale pattern of the air after the cutting.

After locating the reference pixels in the deformed image, as shown in Fig. 3, the strains parallel and normal to the cutting direction $\left(\varepsilon_{x}\right.$ and $\left.\varepsilon_{y}\right)$ for each square in the

$C_{\mathrm{ZNCC}}=\frac{\sum_{i=1}^{m} \sum_{j=1}^{n}\{F(i, j)-\bar{F}\} \times\{G(i+u, j+v)-\bar{G}\}}{\sqrt{\sum_{i=1}^{m} \sum_{j=1}^{n}\{F(i, j)-\bar{F}\}^{2}} \times \sqrt{\sum_{i=1}^{m} \sum_{j=1}^{n}\{G(i+u, j+v)-\bar{G}\}^{2}}}\left(-1 \leq C_{\mathrm{ZNCC}} \leq 1\right)$,

where $u$ and $v$ are the displacement components of the reference pixel in $x$ (longitudinal) and $y$ (tangential) directions, respectively, $F(i, j)$ and $G(i+u, j+v)$ are the grayscale values of the pixel $(i, j)$ and $(i+u, j+v)$ in the reference and target subsets, respectively, $\bar{F}$ and $\bar{G}$ are the averages of the grayscale values of the reference and target subsets, respectively, and $m$ and $n$ are the width and height of the subsets, respectively. The combination of $u$ and $v$ that gives the maximum value of $C_{\mathrm{ZNCC}}$ was determined, which means that the position of reference pixel in the deformed images was determined. Pixel interpolation was conducted to estimate the displacement components $(u, v)$ smaller than a pixel. The interval of the two neighboring reference pixels was equally divided into $2^{7}$ parts by the grid were calculated by the following two formulas:

$$
\begin{aligned}
\varepsilon_{x}= & \frac{1}{2}\left(\frac{\left\{\left(x_{\mathrm{b}}+u_{\mathrm{b}}\right)-\left(x_{\mathrm{a}}+u_{\mathrm{a}}\right)\right\}-\left(x_{\mathrm{b}}-x_{\mathrm{a}}\right)}{\left(x_{\mathrm{b}}-x_{\mathrm{a}}\right)}\right. \\
& \left.+\frac{\left\{\left(x_{\mathrm{d}}+u_{\mathrm{d}}\right)-\left(x_{\mathrm{c}}+u_{\mathrm{c}}\right)\right\}-\left(x_{\mathrm{d}}-x_{\mathrm{c}}\right)}{\left(x_{\mathrm{d}}-x_{\mathrm{c}}\right)}\right), \\
\varepsilon_{y}= & \frac{1}{2}\left(\frac{\left\{\left(y_{\mathrm{a}}+v_{\mathrm{a}}\right)-\left(y_{\mathrm{c}}+v_{\mathrm{c}}\right)\right\}-\left(y_{\mathrm{a}}-y_{\mathrm{c}}\right)}{\left(y_{\mathrm{a}}-y_{\mathrm{c}}\right)}\right. \\
& \left.+\frac{\left\{\left(y_{\mathrm{b}}+v_{\mathrm{b}}\right)-\left(y_{\mathrm{d}}+v_{\mathrm{d}}\right)\right\}-\left(y_{\mathrm{b}}-y_{\mathrm{d}}\right)}{\left(y_{\mathrm{b}}-y_{\mathrm{d}}\right)}\right),
\end{aligned}
$$


Fig. 3 Reference pixels in reference and deformed images with the variables defined

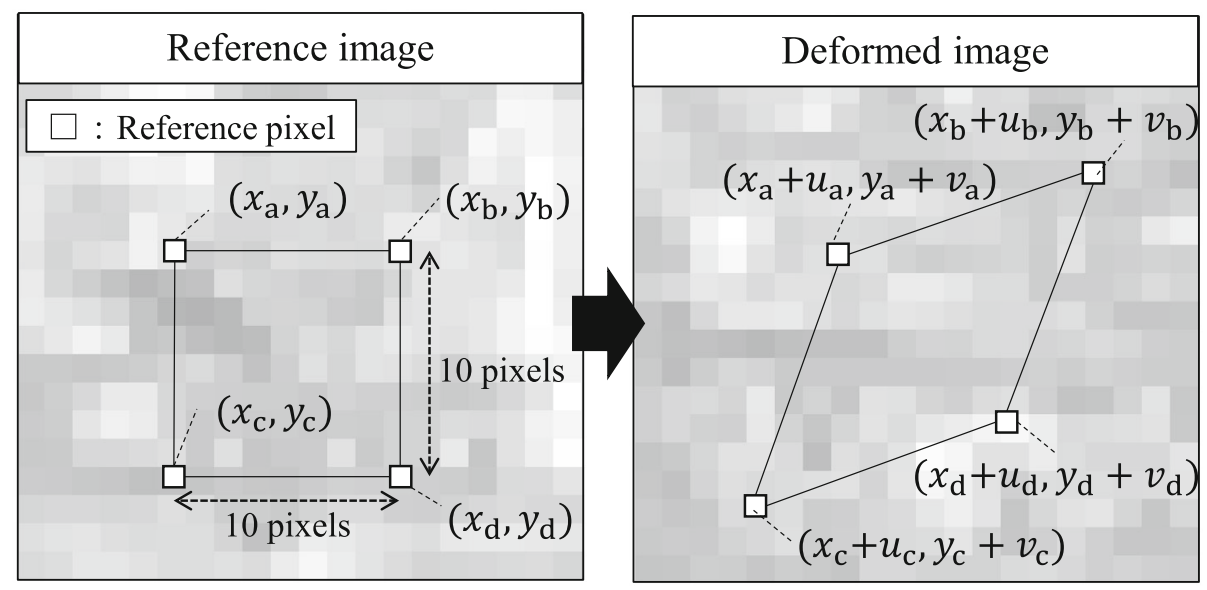

where $x_{k}$ and $y_{k}(k=\mathrm{a}, \mathrm{b}, \mathrm{c}, \mathrm{d})$ are the $x$ and $y$ coordinates of the four reference pixels in the reference image in Fig. 3, respectively, and $u_{k}$ and $v_{k}(k=\mathrm{a}, \mathrm{b}, \mathrm{c}, \mathrm{d})$ are the displacement components of the four reference pixels, respectively. Each square in the grid was colored based on its strain, so that the strain distribution in the ROI would be displayed as a contour map. The minimum displacement the DIC program could measure was $0.8 \times 10^{-2}$ pixel, while the original length of each side of the square in the grid was 10 pixel. Thus, the DIC program could not measure strain smaller than $0.8 \times 10^{-2}$ pixel/10 pixel $\cong$ $0.08 \%$ for each side of the square in the grid. The theoretically estimated accuracy of the DIC program seemed to be high enough to measure the actual strain of several percents due to the cutting, although the following two validation tests were conducted to confirm the precision of the DIC program.

\section{Validation tests}

In the first validation experiment, a couple of images was captured with the interval of $1 \mathrm{~s}$ during the feeding of the tool without cutting. The former image was designated as a reference image and latter one imaginal deformed image. The ROI was placed at the center of the reference image. The strain was analyzed for each square of the grid using the DIC program. The average and the standard deviation of the strain of all 300 squares in the grid were calculated. Although the cutting was not conducted, imaginary strain was distributed randomly in the ROI. This imaginary strain was probably due to the fluctuation of the light illumination. The imaginary strain $\varepsilon_{x}$ was $2.6 \times 10^{-4} \%$ in average and the standard deviation was $5.9 \times 10^{-2} \%$, while the imaginary strain $\varepsilon_{y}$ was $3.4 \times 10^{-3} \%$ in average and the standard deviation was $6.2 \times 10^{-2} \%$. The imaginary strains in both directions were considered to be negligible, since they were so small compared to the strain due to the cutting process.

In the second validation experiment, a reference image was numerically compressed in horizontal direction (L direction) to obtain artificially deformed images. This resizing process of reference image was conducted using MATLAB (2016). The interpolation method used in this image process was bicubic interpolation. The ROI was placed at the center of the reference image and the strain in horizontal direction $\left(\varepsilon_{x}\right)$ was measured for each square of the grid. The reference image was also compressed vertically to measure the strain in vertical direction $\left(\varepsilon_{y}\right)$ in the same manner. The average and the standard deviation of the strain of all 300 squares in the grid were plotted against the artificial strain in Fig. 4. As can be seen in Fig. 4, the mean of the strain $\varepsilon_{x}$ and $\varepsilon_{y}$ calculated by the DIC program seemed to agree with the artificial compression strain, although the standard deviation became larger as the artificial compression strain increased. This was probably because the grayscale patterns of subset have greatly changed as the reference image undergone large deformation. The fractional part of the calculated strain was not deeply discussed in this study due to the large standard deviation. The standard deviation of $\varepsilon_{x}$ was over $0.5 \%$ for the $2 \%$ artificial strain. Thus, $2 \%$ or larger $\varepsilon_{x}$ was not deeply discussed in this study. The increase in the standard deviation of $\varepsilon_{y}$ was slighter than that of $\varepsilon_{x}$, although $\varepsilon_{y}$ larger than $3 \%$ should not be deeply discussed, as the large standard deviation shows.

\section{X-ray CT scanning}

The finished surface and subsurface structure of every workpiece were scanned by microfocus X-ray CT system (SMX-100CT, SHIMADZU) after the cutting experiment. The FOV of the CT system was a cube with edge length of $0.7 \mathrm{~mm}$. The voxel size of the CT image was 


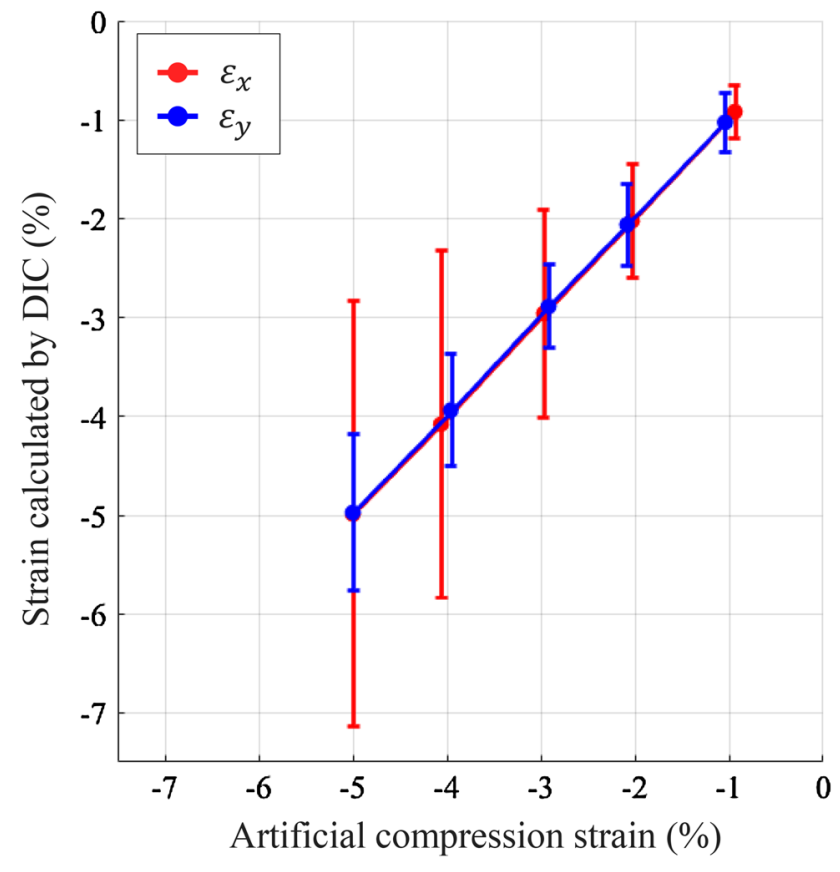

Fig. 4 Strain calculated by the DIC program compared with the artificial compression strain. Error bar shows the standard deviation

approximately $1.4 \times 10^{-3} \mu \mathrm{m} /$ voxel. The distance from the X-ray source to the specimen was $15.0 \mathrm{~mm}$. The distance from the X-ray source to the image intensifier was $500.0 \mathrm{~mm}$. The $\mathrm{X}$-ray tube voltage and the $\mathrm{X}$-ray tube current were $30 \mathrm{kV}$ and $100 \mu \mathrm{A}$, respectively.

\section{Results and discussion}

\section{Strain parallel to the cutting direction}

Figure 5a shows an example of the distribution of strain parallel to the cutting direction $\left(\varepsilon_{x}\right)$ during the cutting, while Fig. $5 \mathrm{~b}$ shows the distribution of residual strain parallel to the cutting direction $\left(\varepsilon_{x \mathrm{r}}\right)$ after the cutting. The photo of the workpiece in Fig. $5 \mathrm{~b}$ was captured approximately $1 \mathrm{~s}$ after the one in Fig. 5a. The cutting angle employed was $40^{\circ}$, while the depth of cut employed was $0.1 \mathrm{~mm}$ for this workpiece. The surface of the workpiece seemed to naturally have the random speckle pattern for applying DIC method, so no surface decoration was applied. The ROI in Fig. 5 was placed approximately $0.04 \mathrm{~mm}$ (20 pixel) apart from the path of the cutting edge, so that the subsets located in the upper side of the ROI would not contain the featureless grayscale pattern of the air after the chip was removed. The squares in the grid where strain was $3 \%$ and those larger than $3 \%$ were both colored in the same color. The strain distribution in Fig. 5a shows that tensile strain $\varepsilon_{x}$ is detected only near the cutting
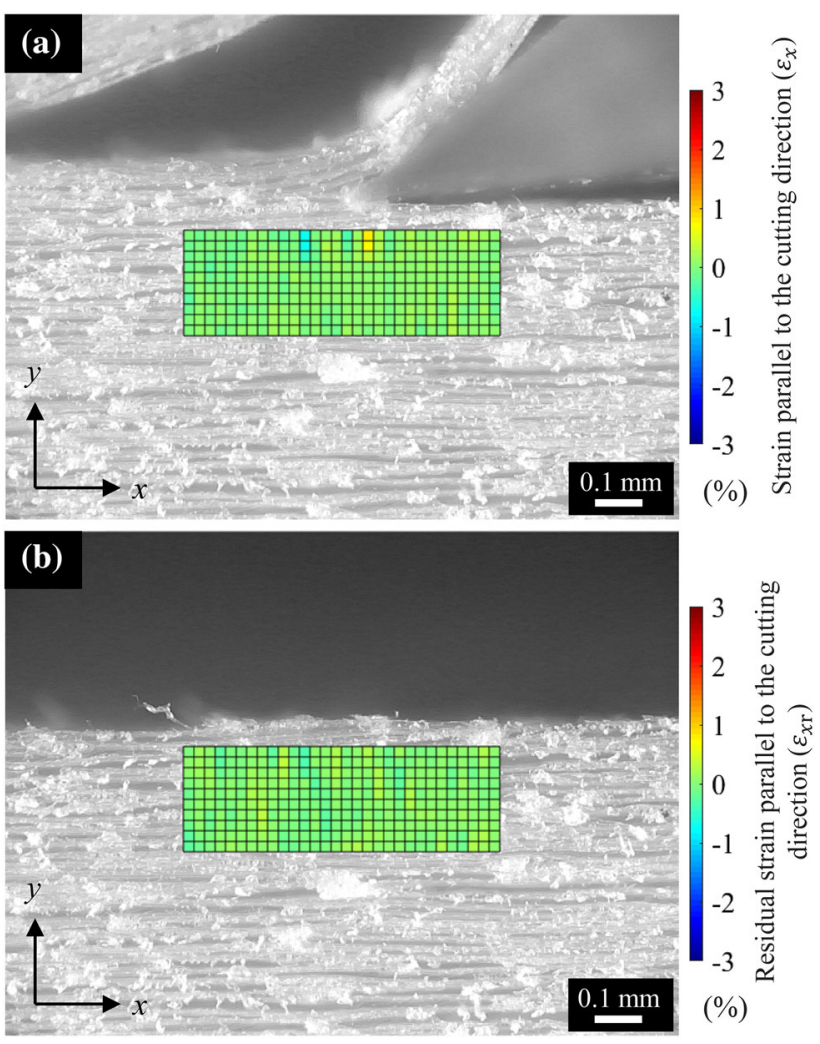

Fig. 5 Distribution of the strain parallel to the cutting direction $\left(\varepsilon_{x}\right.$ and $\varepsilon_{x \mathrm{r}}$ ). Depth of cut was $0.1 \mathrm{~mm}$; cutting angle was $40^{\circ}$. a Distribution of the strain $\varepsilon_{x}$ during the cutting. b Distribution of the residual strain $\varepsilon_{x \mathrm{r}}$ after the cutting. The image in $\mathbf{b}$ was taken $1 \mathrm{~s}$ after the image in a

edge. The rest of the area showed green, which means that almost no significant strain occurred during the cutting. In addition, the strain distribution after the cutting (Fig. 5b) shows that almost no residual strain $\varepsilon_{x \mathrm{r}}$ was detected. This means that the cells located beneath the finished surface are keeping its original length in L direction. This was probably because the yield stress of wood is naturally large in the $\mathrm{L}$ direction.

Other examples of the distribution of the strain $\varepsilon_{x}$ and $\varepsilon_{x \mathrm{r}}$ are shown in Fig. 6a, b, respectively. The cutting angle was $70^{\circ}$, while the depth of cut was $0.3 \mathrm{~mm}$ for this workpiece. As the cutting angle and the depth of cut became larger than those in Fig. 5, the parallel cutting force component has probably increased, and tensile strains $\varepsilon_{x}$ and $\varepsilon_{x \mathrm{r}}$ larger than $1 \%$ were detected in the ROI (Fig. 6a, b). The tensile strains $\varepsilon_{x}$ and $\varepsilon_{x \mathrm{r}}$ seemed to be distributed randomly in the ROI. This was probably due to the local stress concentration when the cutting force was applied to the ray tissue which widely distributed in the workpiece.

The average residual strain $\varepsilon_{x \mathrm{r}}$ along the horizontal (longitudinal) line $0.10 \mathrm{~mm}$ beneath the path of the cutting edge was calculated for each times of cutting, and was designated as $\varepsilon_{x \mathrm{r}} \_.10 \mathrm{~mm}$. Figure 7 shows the relationship 

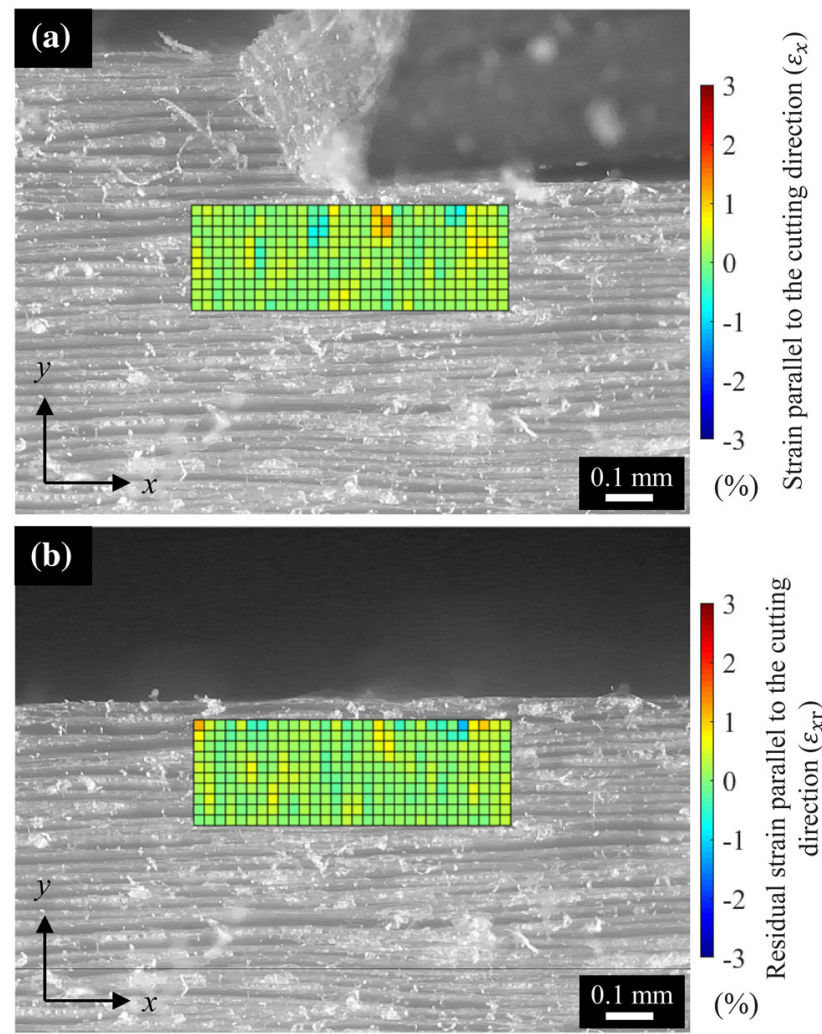

Fig. 6 Distribution of the strain parallel to the cutting direction $\left(\varepsilon_{x}\right.$ and $\varepsilon_{x \mathrm{r}}$ ). Depth of cut was $0.3 \mathrm{~mm}$; cutting angle was $70^{\circ}$

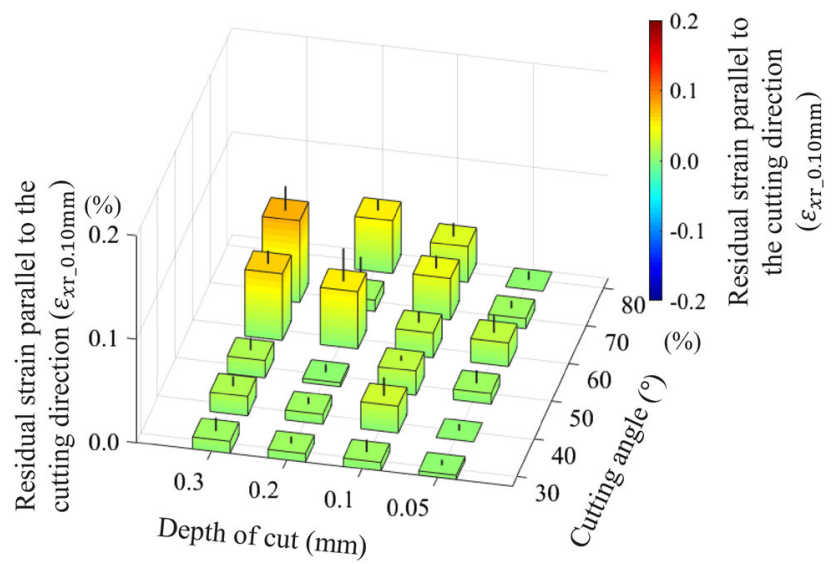

Fig. 7 Relationship of the residual strain $\varepsilon_{x \mathrm{x}} 0.10 \mathrm{~mm}$ to the depth of cut and the cutting angle. The color of each bar corresponds to the value of residual strain $\varepsilon_{x \mathrm{r}}-0.10 \mathrm{~mm}$. Error bar represents the standard error. The data are not shown for the cutting angle and the depth of cut, $80^{\circ}$ and $0.3 \mathrm{~mm}$, respectively, since the strain was measured only two times (color figure online)

between the residual strain $\varepsilon_{x \mathrm{r}}-0.10 \mathrm{~mm}$ and the cutting condition. The height of the bar represents the mean of the residual strain $\varepsilon_{x \mathrm{r} \_} 0.10 \mathrm{~mm}$, while the error bar represents the standard error, of five times of cutting. When the cutting
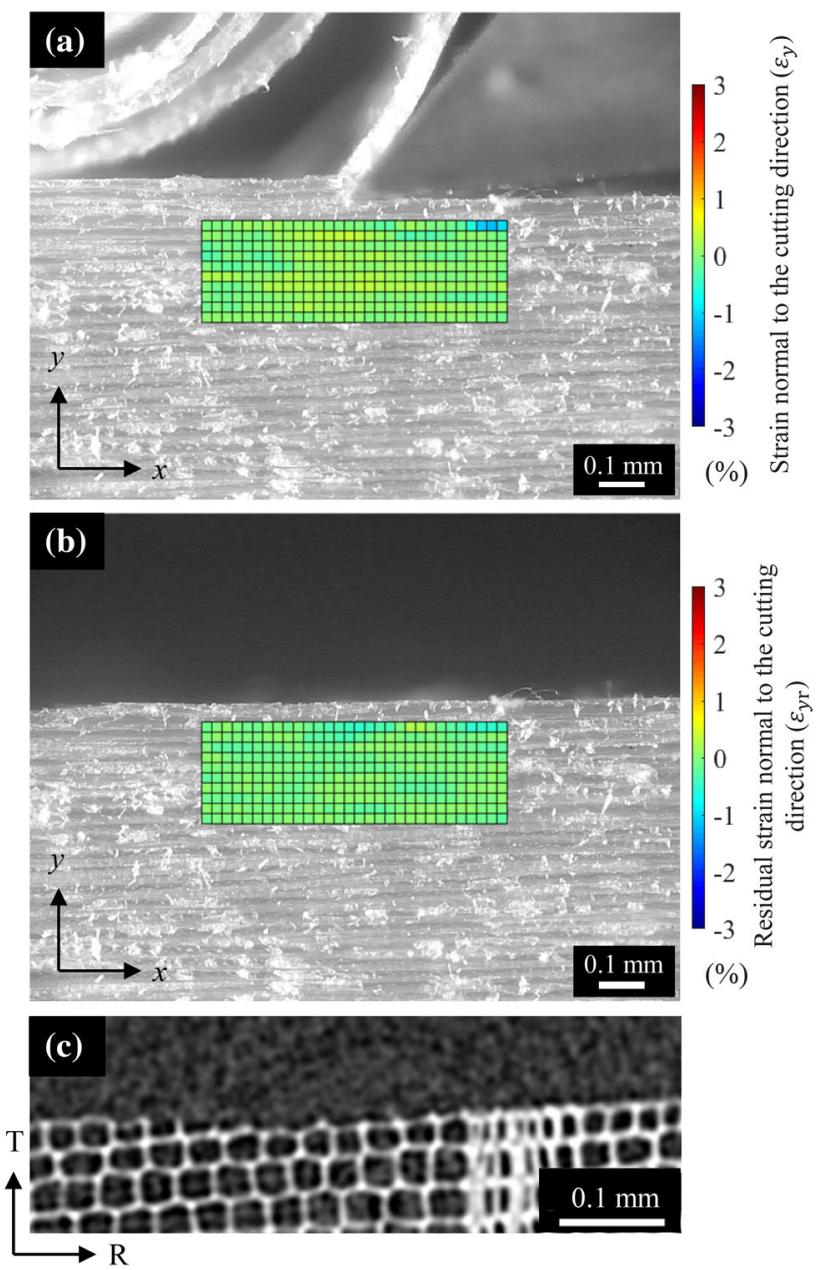

Fig. 8 Distribution of the strain normal to the cutting directions $\left(\varepsilon_{y}\right.$ and $\varepsilon_{y r}$ ) and the CT image of the workpiece. Depth of cut was $0.05 \mathrm{~mm}$; cutting angle was $50^{\circ}$. a Distribution of the strain $\varepsilon_{y}$. b Distribution of the residual strain $\varepsilon_{y r}$. c Cross-sectional view (RT plane) of the workpiece obtained by X-ray CT scanning

angle or the depth of cut was large, the deformation arose within $0.10 \mathrm{~mm}$ from the path of the cutting edge was so severe that the DIC program sometimes failed to track reference pixels located in those areas. Therefore, the strain in those areas could not be always measured, and thus, the standard error tended to be large for those cutting conditions. The strain was measured only twice when the cutting angle was $80^{\circ}$ and the depth of cut $0.3 \mathrm{~mm}$, so its data are not drawn in the figure. Figure 7 shows that the residual strain $\varepsilon_{x \mathrm{r}}$ becomes larger in accordance with the cutting angle and the depth of cut.

\section{Strain normal to the cutting direction}

Figure $8 \mathrm{a}, \mathrm{b}$ shows examples of the distribution of strain normal to the cutting direction $\left(\varepsilon_{y}\right)$ and the residual strain $\left(\varepsilon_{y \mathrm{r}}\right)$, respectively, when the cutting angle of $50^{\circ}$ and the 
depth of cut of $0.05 \mathrm{~mm}$ were employed. When the cutting angle was $60^{\circ}$ or smaller, while the depth of cut was $0.05 \mathrm{~mm}$, a thin chip was generated and it smoothly slid up the rake face of the tool, as shown in Fig. 8a. There seemed to be no stress of significant level occurred in the workpiece. Almost no residual strain $\varepsilon_{y \mathrm{r}}$ was detected in the ROI (Fig. 8b). This means that, in other words, the damage in the subsurface layers of the workpiece is small. The CT image in Fig. 8c shows a cross-sectional view of the same workpiece with Fig. 8a, b, which was cut at an arbitrary plane normal to the $\mathrm{L}$ direction. The vertical direction of the $\mathrm{CT}$ image is $\mathrm{T}$ direction, while the horizontal direction is $\mathrm{R}$ direction. The grayscale value of a pixel in a CT image represents its density, so the cell walls are shown in brighter color than the cell lumen. Most of the cells on and beneath the finished surface seemed to keep its original form, as presumed from Fig. 8b.

As the depth of cut became $0.1 \mathrm{~mm}$ or larger, a split originated near the cutting edge tended to travel ahead of the tool until the chip was broken down at the tip of the
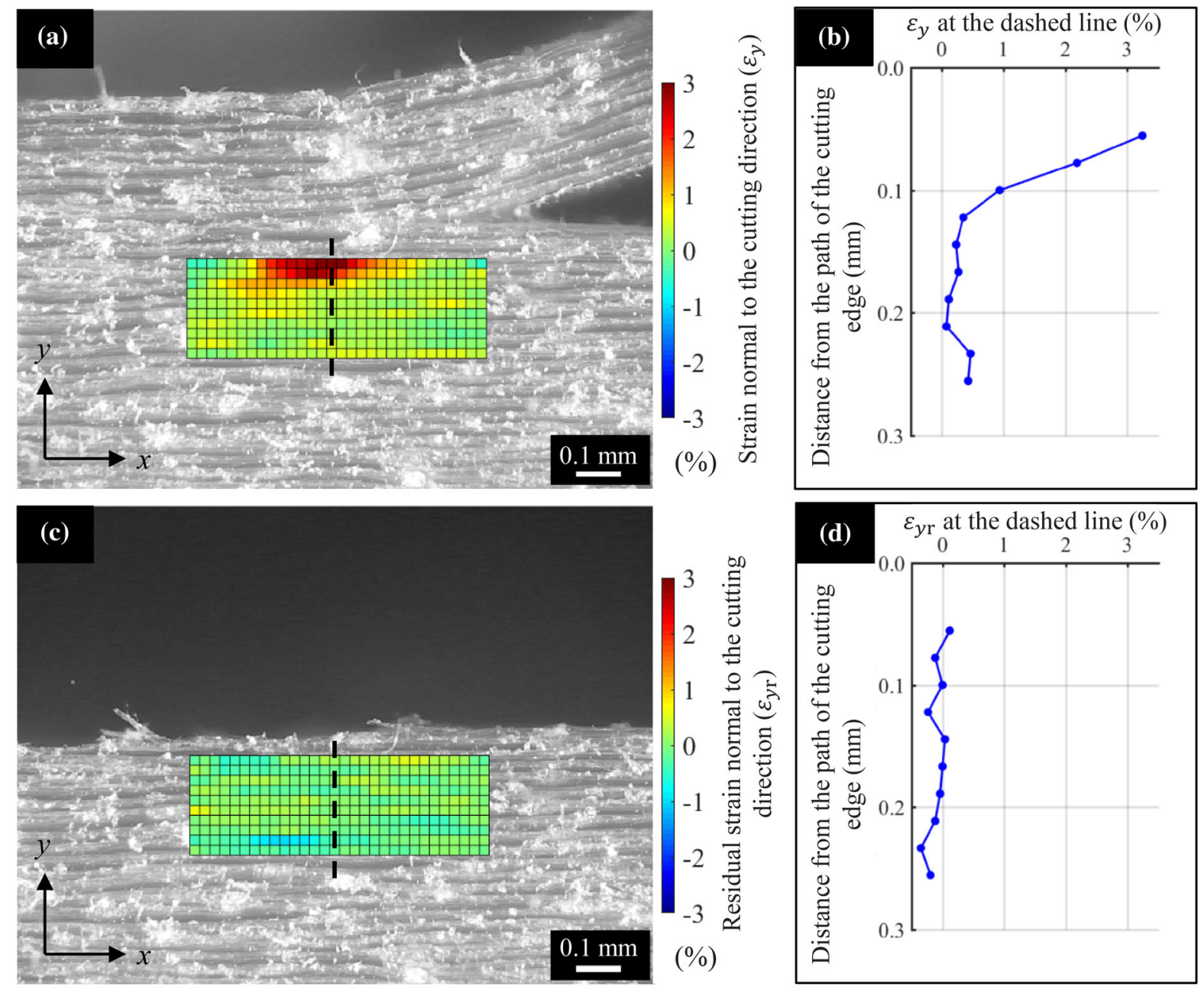

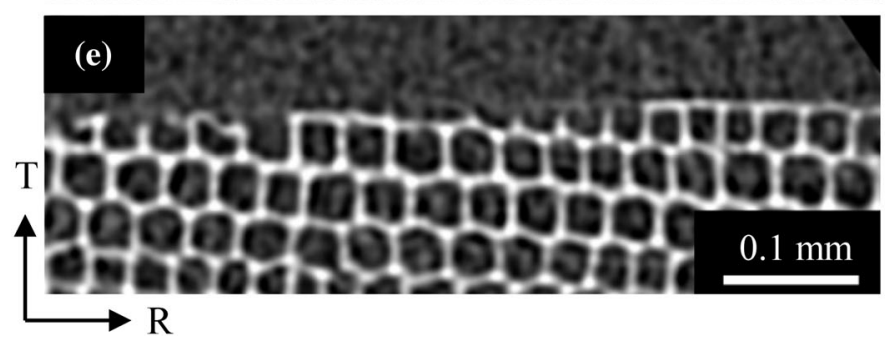

Fig. 9 Distribution of the strain normal to the cutting direction $\left(\varepsilon_{y}\right.$ and $\varepsilon_{y \mathrm{r}}$ ) and CT image of the workpiece. Depth of cut was $0.3 \mathrm{~mm}$; cutting angle was $50^{\circ}$. a Distribution of the strain $\varepsilon_{y}$. b Strain $\varepsilon_{y}$ detected along the dashed line drawn in a. c Distribution of the residual strain $\varepsilon_{y \mathrm{r}}$. d Residual strain $\varepsilon_{y \mathrm{r}}$ detected along the dashed line drawn in c. e Cross-sectional view (RT plane) of the workpiece obtained by X-ray CT scanning 
crack in bending. This split ahead of the cutting edge is often called "fore-split". After the chip broke down, it slid up the rake face of the tool until the cutting edge reaches to the tip of the split. When the fore-split was observed, tensile strain $\varepsilon_{y}$ larger than $2 \%$ was detected near the tip of the split (Fig. 9a). The values of $\varepsilon_{y}$ and $\varepsilon_{y r}$ detected along the dashed line drawn in Fig. 9a, c are plotted in the graphs in Fig. 9b, d, respectively. The tensile strain $\varepsilon_{y}$ almost fully recovered after the cutting, as can be seen from Fig. 9c, d. Moreover, the cells in the CT images seemed to keep in its original form (Fig. 9e). These results suggest that this tensile strain $\varepsilon_{y}$ induced by the fore-split have not led to any apparent damage in subsurface cell layers. However, the tissue might have split along intercellular layers and then returned back to its original position. The resolution of the CT image was not high enough to determine whether the cells were still bonded together or not. In the practical wood cutting, such fore-splits should be avoided.

When the cutting angle was $70^{\circ}$ or larger, the chip formation was unstable and the chip was generated without clear fore-split, regardless of the depth of cut employed. Compression strain $\varepsilon_{y}$ was detected deep under the
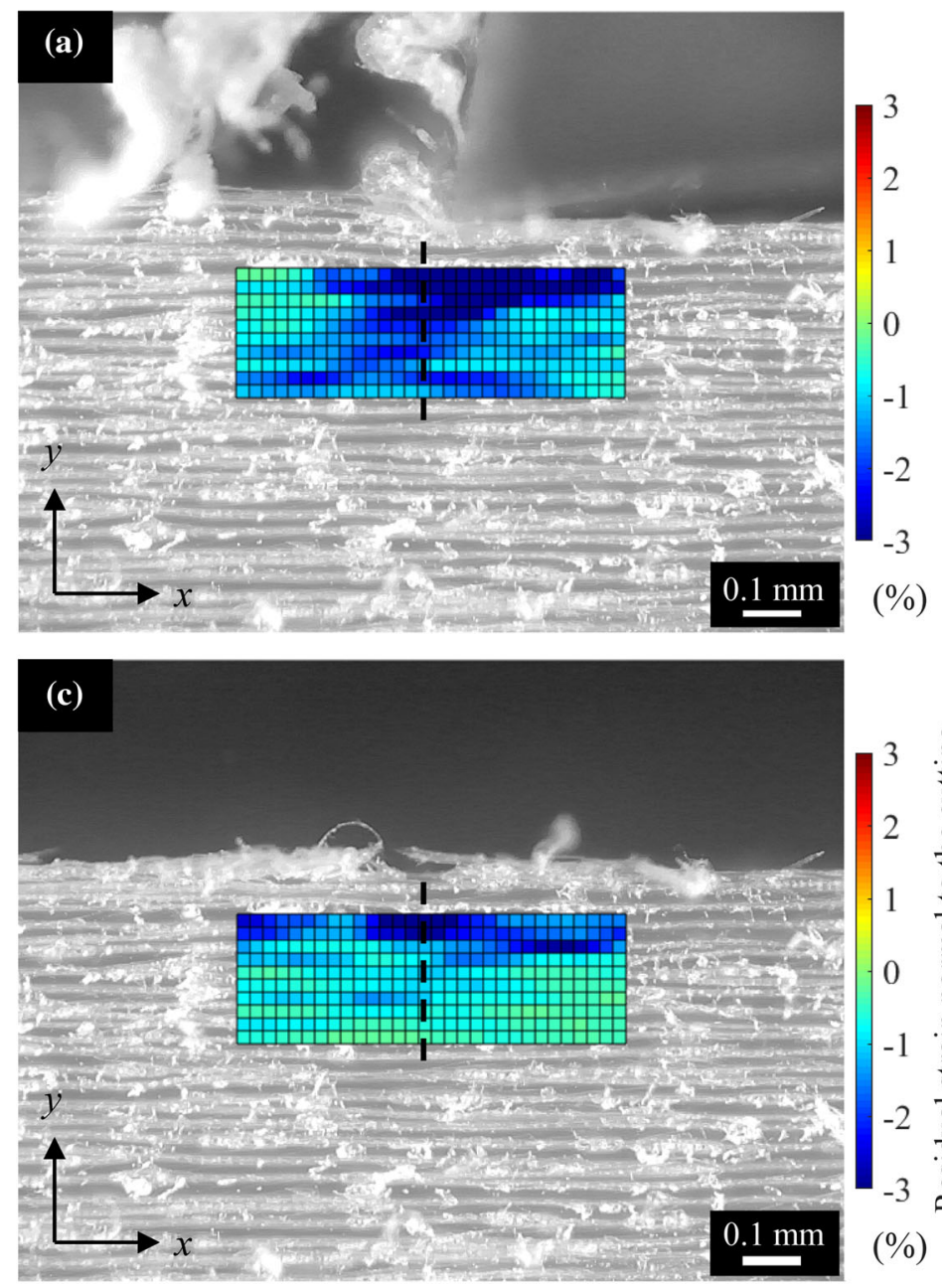
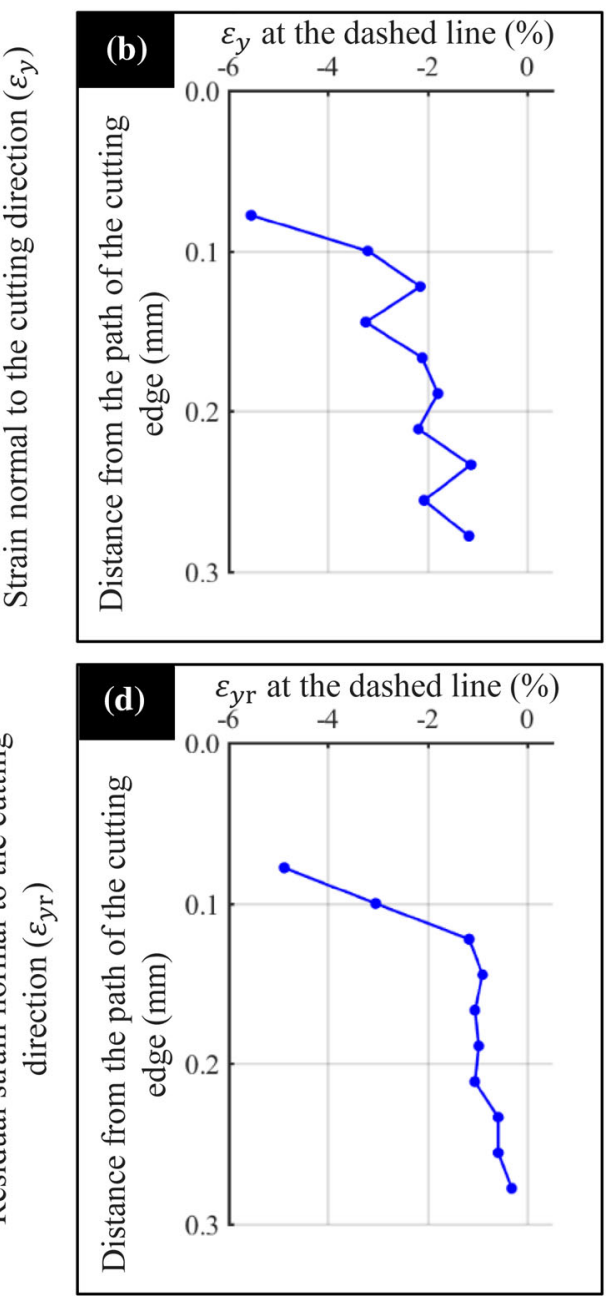

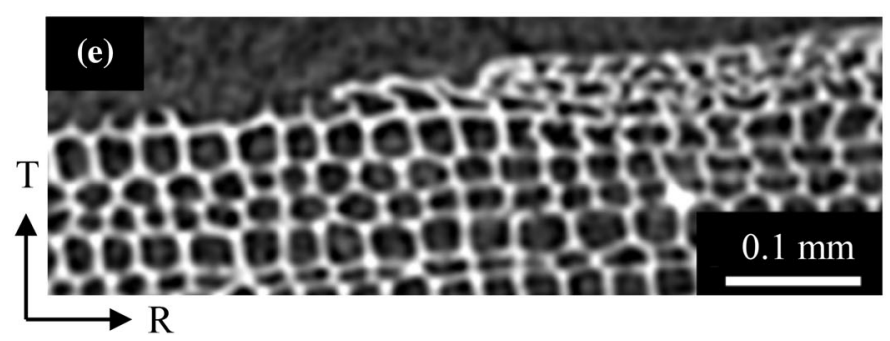

Fig. 10 Distribution of strain normal to the cutting direction $\left(\varepsilon_{y}\right.$ and $\left.\varepsilon_{y \mathrm{r}}\right)$ and CT image of the workpiece. Depth of cut was $0.05 \mathrm{~mm}$; the cutting angle was $80^{\circ}$ 


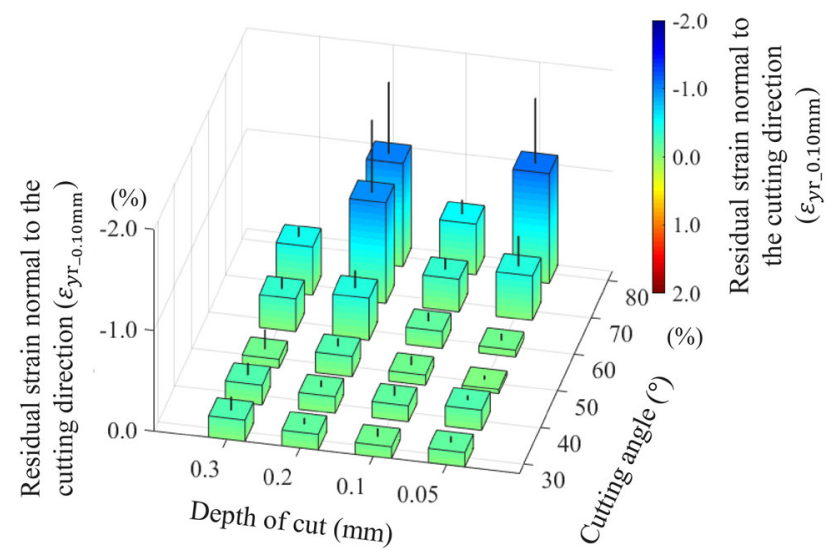

Fig. 11 Relationship of residual strain $\varepsilon_{y r} \_0.10 \mathrm{~mm}$ to the depth of cut and the cutting angle. Error bar represents the standard error

workpiece during the cutting (Fig. 10a, b). The compression strain near the finished surface has not recovered after the cutting (Fig. 10c, d). These results indicate that the normal cutting force increased as the cutting angle increased. The compression strains $\varepsilon_{y}$ and $\varepsilon_{y \mathrm{r}}$ randomly distributed in deeper areas. These randomly occurred compression strain can be attributed to the ray tissue which widely distributed in the workpiece. The graph in Fig. 10d indicates that the cells located within $0.10 \mathrm{~mm}$ from the path of the cutting edge have compressed in $\mathrm{T}$ direction. Moreover, in the CT image of Fig. 10e, the lumen of the cells located within $0.05 \mathrm{~mm}$ from the finished surface appeared to be extremely compressed in $\mathrm{T}$ direction.

Figure 11 shows the relationship between the residual strain $\varepsilon_{y r} \_0.10 \mathrm{~mm}$ and the cutting condition. As can be seen from Fig. 11, the residual strain $\varepsilon_{y r} \_.10 \mathrm{~mm}$ was small when the cutting angle was $60^{\circ}$ or smaller, and the relation of $\varepsilon_{y r} \_0.10 \mathrm{~mm}$ to the depth of cut and the cutting angle was not clear. Figure 11 shows that $\varepsilon_{y r} \_0.10 \mathrm{~mm}$ increased sharply as the cutting angle became $70^{\circ}$ or larger, although the relation between $\varepsilon_{y r} \_0.10 \mathrm{~mm}$ and depth of cut was not clear as large standard error shows. The absolute value of the residual strain $\varepsilon_{y r} \_0.10 \mathrm{~mm}$ was approximately ten times larger than that of $\varepsilon_{x r} \_.10 \mathrm{~mm}$ (Fig. 7). This is because the yield stress of wood is larger in $\mathrm{L}$ direction than in $\mathrm{T}$ direction. Therefore, the relation between the cutting condition and the residual strain $\varepsilon_{y \mathrm{r}}$ is more important for preventing the subsurface damage.

The strain distribution in the wood cutting was easily measured using the DIC method. However, the DIC program could not measure strain in the regions closest to the finished surface, because the subset should contain the featureless grayscale pattern of the air after the chip was removed. It was suggested from the CT image that there might have been a considerable residual strain $\varepsilon_{y r}$ in these region. The relation between the subsurface damage and the cutting condition should be more comprehensively understood by clarifying the strain distribution in those regions.

\section{Conclusion}

The two-dimensional residual strain distribution beneath the finished surface of hinoki (Chamaecyparis obtusa) in slow-speed orthogonal cutting was analyzed using the DIC method, to evaluate the subsurface damage. The relation between the subsurface damage and the cutting condition was discussed from the viewpoint of the residual strain data.

The absolute value of the residual strain parallel to the cutting direction (L direction) was small compared to that of the strain normal to the cutting direction. This was probably because the yield stress of wood is naturally larger in $\mathrm{L}$ direction than in $\mathrm{T}$ direction, although the parallel component of the cutting force should be larger than the normal one.

The compression strain normal to the cutting direction near the cutting edge increased with increasing cutting angle, and it remained to some extent as residual strain. On the other hand, the tensile strain normal to the cutting direction induced by the fore-split recovered soon after the cutting. However, the tissue adjacent to the fore-split should have been separated along intercellular layers, which means that those cells might be no longer bonded together.

The residual strain analysis using DIC method was found to be suitable for the non-contact evaluation of the damage in the cell layers beneath the finished surface, although there was limitation of positioning the ROI and measurement threshold. It was confirmed that the subsurface damages may occur depending on the cutting condition employed. The mechanism for occurrence of the machining defects, which is deeply related to the subsurface damage, could be further clarified by analyzing the residual strain beneath the finished surface using the DIC method.

Acknowledgements This research was supported by research Grant \#201426 of Forestry and Forest Products Research Institute. Authors would like to express sincere thanks to Kanefusa Corporation for providing the cutting tools and to Food Research Institute (NARO) for the X-ray CT system.

\section{References}

1. Stewart HA, Crist JB (1982) SEM examination of subsurface damage of wood after abrasive and knife planing. Wood Sci 14(3):106-109 
2. Matsuda Y, Fujiwara Y, Fujii Y (2015) Observation of machined surface and subsurface structure of hinoki (Chamaecyparis obtusa) produced in slow-speed orthogonal cutting using X-ray computed tomography. J Wood Sci 61:128-135

3. Kinoshita N (1984) Analysis of the veneer-formation process III: analysis of cutting stress by the photo elastic coating method (in Japanese). Mokuzai Gakkaishi 30(1):32-37

4. Tochigi T, Tadokoro C (1985) Change of cutting stress in the progression of the dulling of the tool edge. Mokuzai Gakkaishi 31(11):880-887

5. Huang Y, Hayashi D (1973) Basic analysis of mechanism in wood-cutting stress analysis in orthogonal cutting parallel to grain (in Japanese). Mokuzai Gakkaishi 19(1):7-12

6. Sugiyama S (1974) Fundamental studies on mechanism of veneer cutting VI: numerical analysis of stress distribution in workpiece during cutting with sharp bar. Mokuzai Gakkaishi 20(6):257-263

7. Sugiyama S (1975) Fundamental studies on mechanism of veneer cutting VII: numerical analysis of stress distribution in workpiece during cutting without pressure bar (2) (in Japanese). Mokuzai Gakkaishi 21(1):15-21

8. Palka LC (1975) Veneer-cutting analysis by an elastic finiteelement model: a case study. Wood Sci 8(2):97-104

9. Triboulot P, Asano I, Ohta M (1983) An application of fracture mechanics to the wood-cutting process. Mokuzai Gakkaishi 29(2):111-117

10. Kinoshita N (1983) Analysis of the veneer-formation process II: numerical analysis of cutting stress in lathe check formation by finite element method (in Japanese). Mokuzai Gakkaishi 29(12):877-883

11. McKenzie WM (1969) Applying grid patterns to wood surfaces using photosensitive lacquers. For Prod J 19(2):43-44

12. McKenzie WM, Karpovich H (1975) Measured strains in slow linear veneer cutting: effects of nosebar form and gap. Wood Sci Technol 9(3):213-231

13. Peters WH, Ranson WF (1982) Digital imaging techniques in experimental stress analysis. Opt Eng 21(3):427-431

14. Sutton MA, Wolters WJ, Peters WH, Ranson WF, McNeill SR (1983) Determination of displacements using an improved digital correlation method. Image Vis Comput 1(3):133-139

15. Sutton MA, Orteu JJ, Schreier HW (2009) Image correlation for shape, motion and deformation measurements basic concepts, theory and applications. Springer, New York

16. Jeong GY, Zink-Sharp A, Hindman DP (2010) Applying digital image correlation to wood strands: influence of loading rate and specimen thickness. Holzforschung 64:729-734

17. Pan B, Lu Z, Xie H (2010) Mean intensity gradient: an effective global parameter for quality assessment of the speckle patterns used in digital image correlation. Opt Lasers Eng 48:469-477

18. Choi D, Thorpe JL, Hanna RB (1991) Image analysis to measure strain in wood and paper. Wood Sci Technol 25:251-262

19. Zink AG, Davidson RW, Hanna RB (1995) Strain measurement in wood using a digital image correlation technique. Wood Sci Technol 27(4):346-359

20. Choi D, Thorpe JL, Cote WA, Hanna RB (1996) Quantification of compression failure propagation in wood using digital image pattern recognition. For Prod J 46(10):87-93

21. Stelmokas JW, Zink AG, Loferski JR (1997) Image correlation analysis of multiple-bolt wood connections. Wood Fiber Sci 29(3):210-227
22. Zink AG, Hanna RB, Stelmokas JW (1997) Measurement of Poisson's ratios for yellow-poplar. For Prod J 47(3):78-80

23. Murata K, Masuda M, Ichimaru M (1999) Analysis of radial compression behavior of wood using digital image correlation method (in Japanese). Mokuzai gakkaishi 45(5):375-381

24. Murata K, Masuda M (2003) Analysis of strain distribution of softwood in transverse compression measured by digital image correlation method (in Japanese). Zairyo 52(4):347-352

25. Ljungdahl J, Berglund LA, Burman M (2006) Transverse anisotropy of compressive failure in European oak-a digital speckle photography study. Holzforschung 60:190-195

26. Samarasinghe S, Kulasiri GD (2000) Displacement fields of wood in tension based on image processing: part 1. Tension paralleland perpendicular-to-grain and comparisons with isotropic behaviour. Silva Fenn 34(3):261-274

27. Jernkvist LO, Thuvander F (2001) Experimental determination of stiffness variation across growth rings in Picea abies. Holzforschung 55:309-317

28. Sjödin J, Serrano E, Enquist B (2006) Contact-free measurements and numerical analyses of the strain distribution in the joint area of steel-to-timber dowel joints. Holz Roh- Werkst 64:497-506

29. Miyauchi K, Masuda M, Murata K (2006) Analysis of strain distributions of wooden dovetail joints using digital image correlation method (in Japanese). Zairyo 55(4):367-372

30. Miyauchi K, Murata K (2007) Strain-softening behavior of wood under tension perpendicular to the grain. J Wood Sci 53:463-469

31. Keunecke D, Niemz P (2008) Axial stiffness and selected structural properties of yew and spruce microtensile specimens. Wood Res 53(1):1-14

32. Jeong GY, Hindman DP, Finkenbinder D, Lee JN, Lin Z (2008) Effect of loading rate and thickness on the tensile properties of wood strands. For Prod J 58(10):33-37

33. Jeong GY, Zink-Sharp A, Hindman DP (2009) Tensile properties of earlywood and latewood from loblolly pine (Pinus taeda) using digital image correlation. Wood Sci Technol 41(1):51-63

34. Nagai H, Murata K, Nakano T (2011) Strain analysis of lumber containing a knot during tensile failure. J Wood Sci 57:114-118

35. Jeong GY, Park MJ (2016) Evaluate orthotropic properties of wood using digital image correlation. Constr Build Mater 113:864-869

36. Murata K, Ito M, Masuda M (2001) An analysis of the swelling behavior of various woods using an optical microscope and a digital image correlation method (DIC) (in Japanese). Zairyo 50(4):397-402

37. Kwon O, Hanna R (2010) The enhanced digital image correlation technique for feature tracking during drying of wood. Strain 46:566-580

38. Keunecke D, Novosseletz K, Lanvermann C, Mannes D, Niemz P (2012) Combination of X-ray and digital image correlation for the analysis of moisture-induced strain in wood: opportunities and challenges. Eur J Wood Prod 70:407-413

39. Hellström LM, Gradin PA, Carlberg T (2008) A method for experimental investigation of the wood chipping process. Nord Pulp Pap Res J 23(3):339-342

40. Schneider CA, Rasband WS, Eliceiri KW (2012) NIH Image to ImageJ: 25 years of image analysis. Nat Methods 9:671-675

41. MATLAB (2016) The MathWorks, Inc., Natick, MA, USA

42 Pan B, Xie H, Wang Z (2010) Equivalence of digital image correlation criteria for pattern matching. Appl Opt 49(28):5501-5509 